\title{
EFFECTIVENESS AND SAFETY OF BACILLUS CALMETTE-GUERIN (BCG) VACCINE IN WARTS
}

Chenna Subhashini ${ }^{1}$, T. S. Mohan Rao ${ }^{2}$, Swetha Naidu K3, P. Anila Sunandini4, P. Guru Prasad5, Rupa Ramani6, Shaik Asha7, S. N. R. Chankravarthy ${ }^{8}$

${ }^{1}$ Assistant Professor, Department of DVL, Andhra Medical College.

${ }^{2}$ Associate Professor, Department of DVL, Andhra Medical College.

3Postgraduate Student, Department of DVL, Andhra Medical College.

${ }^{4}$ Professor, Department of DVL, Andhra Medical College.

5 Professor, Department of DVL, Andhra Medical College.

${ }^{6}$ Postgraduate Student, Department of DVL, Andhra Medical College.

${ }^{7}$ Postgraduate Student, Department of DVL, Andhra Medical College.

${ }^{8}$ Postgraduate Student, Department of DVL, Andhra Medical College.

\section{ABSTRACT}

\section{BACKGROUND}

Viral warts are common dermatological diseases caused by human papilloma virus. Immunotherapy has now become the therapeutic modality for treatment of warts. We conducted this study to assess the efficacy and safety of intralesional BCG Vaccine for treatment of warts.

\section{MATERIALS AND METHODS}

We have selected 30 patients belonging to age group 10 to 45 years of both the sexes having multiple warts predominantly common warts and palmoplantar warts. Intralesional BCG vaccine $0.1 \mathrm{~mL}$ was injected into single wart at a time, with prior Mantoux test. Thereafter, remaining lesions were injected with $0.1 \mathrm{~mL}$ BCG vaccine, one lesion at every session with 2 weeks interval for a period of 3 months. Treatment was stopped if there was no response after 5 injections.

Study Design- Uncontrolled clinical trial.

Study Setting- Patients attended in OPD of DVL Department in KGH (affiliated to Andhra Medical College), Visakhapatnam, AP, India.

\section{RESULTS}

Out of 30 patients, 26 patients (86.6\%) had complete resolution of their warts both at the injected and the distant sites. 2 patients $(6 \%)$ had recurrence. Treatment was well tolerated and the side effects were reversible.

\section{CONCLUSION}

Our study results showed the efficacy of BCG vaccine for the treatment of warts comparable with previous studies. It has shown high cure rate at injected as well as distant sites with lower recurrence rates. The treatment is cost effective with minimal treatable side effects.

\section{KEYWORDS}

Warts, Bacillus Calmette-Guerin (BCG), Intralesional, Immunotherapy.

HOW TO CITE THIS ARTICLE: Subhashini C, Rao TSM, Naidu SK, et al. Effectiveness and safety of Bacillus Calmette-Guerin (BCG) vaccine in warts. J. Evolution Med. Dent. Sci. 2017;6(94):6909-6911, DOI: 10.14260/jemds/2017/1497

\section{BACKGROUND}

Warts are benign proliferation of the skin resulting from infection with human papilloma virus (HPV). The therapeutic options available for warts ranging from charning of warts to very sophisticated drugs, point to the fact that none is $100 \%$ effective. It is always advisable to start with a simple, cheap modality and persist with it for a long time. The various modalities of treatment may be categorised as surgical and medical. They can also be categorised as cytodestructive methods, antimetabolite therapy, antiviral therapy and immunomodulatory methods.

'Financial or Other Competing Interest': None.

Submission 17-11-2017, Peer Review 29-12-2017,

Acceptance 01-12-2017, Published 18-12-2017.

Corresponding Author:

Dr. T. S. Mohan Rao,

Flat No. 101, Aparna Apts.,

Akkayapalem,

Visakhapatnam-530016.

E-mail:drtsmohanrao@gmail.com

DOI: $10.14260 / \mathrm{jemds} / 2017 / 1497$
Various immunotherapeutic modalities have been used in the treatment of warts such as purified protein derivative, Mycobacterium W vaccine, MMR vaccine, diphenylcyclopropenone, squaric acid dibutyl ester (SADBE), Imiquimod, tuberculin jelly, interferon alpha and gamma (IFN-gamma), skin test antigens like Candida, mumps, Trichophyton and most recently BCG vaccine.

BCG vaccine is a live, freeze- dried vaccine derived from attenuated strain of Mycobacterium bovis.

The mechanism of action of BCG vaccine includes delayed cell mediated hypersensitivity response against the virus. It depends on activation of CD4 lymphocytes and increase in IL1, IL-2 and TNF-alpha.

IL-1 and TNF-alpha have antiviral effects on HPV through down regulation of its gene transcription.

Previous studies regarding treatment of warts with BCG vaccine have shown significant improvement in the treatment of warts not only at the treated site but also at distant untreated warts. So, we have selected this modality of treatment to clinically assess the efficacy of BCG vaccine in treatment of warts. 


\section{MATERIALS AND METHODS}

This study was conducted in 30 selected patients with informed written consent in DVL Department, King George Hospital, Andhra Pradesh, India.

\section{The inclusion criteria were:}

1. Clinically diagnosed patients with single or multiple common and palmoplantar warts.

2. Age group 10-45 years.

\section{The Exclusion Criteria were:}

1. Immunocompromised patients.

2. Pregnant and lactating women.

3. Mantoux positive.

Patients were treated with $0.1 \mathrm{~mL}$ of intralesional BCG vaccine using an insulin syringe, given to a single wart at each session, repeated at intervals of 2 weeks till there was complete clearance of all warts or maximum of 5 injections. The treatment was stopped if there was no response even after 5 injections of vaccine. Complete clearance of all the warts at treated and untreated sites was considered as a clinical cure. For recurrences and adverse effects patients were followed up for 3 months.

\section{Objectives of the Study}

Assessment of efficacy and safety of BCG vaccine in common and palmoplantar warts.

\section{Study Design}

Uncontrolled clinical trial.

\section{Study Setting}

Patients attended to OPD of DVL Department in KGH (affiliated to Andhra Medical College) Visakhapatnam, AP. India.

\section{RESULTS}

Out of 30 patients, there were 18 males (60\%) and 12 females $(40 \%)$ in the age group 10-45 years. Total number of warts in each patient ranged from 1-20 warts involving the upper limb (forearm, dorsum of the hand, palm, periungual and subungual areas) and lower limb (legs, dorsum of the feet, plantar surface and periungual region of toes). The duration of their lesions ranged from 3 months to two years.

Out of 30 patients, 26 patients $(86.6 \%)$ showed complete recovery, 2 patients $(6 \%)$ showed recurrence and 4 patients (13.3\%) showed no response.

\begin{tabular}{|c|c|}
\hline Age Group & No. of Patients \\
\hline $1-10$ & 1 \\
\hline $11-20$ & 19 \\
\hline $21-30$ & 6 \\
\hline $31-40 \quad$ Among 30 Patients \\
\hline \multicolumn{2}{|c|}{} \\
\hline
\end{tabular}

\begin{tabular}{|c|c|}
\hline Occupation of the Patient & Number of Patients \\
\hline Student & 17 \\
\hline Housewife & 05 \\
\hline Manual labourer & 03 \\
\hline Other job & 05 \\
\hline \multicolumn{2}{|c|}{ Among 30 Patients } \\
\hline
\end{tabular}

\begin{tabular}{|c|c|}
\hline $\begin{array}{c}\text { Total no. of Injections Needed for } \\
\text { Complete Clearance }\end{array}$ & $\begin{array}{c}\text { No. of Patients with } \\
\text { Complete Clearance }\end{array}$ \\
\hline 1 & 12 \\
\hline 2 & 08 \\
\hline 3 & 03 \\
\hline 4 & 02 \\
\hline 5 & 01 \\
\hline No response & 04 \\
\hline
\end{tabular}

Among 30 patients, Number of Injections (Once in every 2 Weeks Required for Complete Clearance in Each Patient)

Out of 27 patients with complete clearance of warts, two patients had recurrence of warts at different places other than previously injected site after 2 months of completion of treatment.

The local side effects like redness and swelling were presented in 3 patients (10\%) within a week after their first dose of injection. They were treated with Tablet Paracetamol $650 \mathrm{mg}$ t.i.d. and capsule Amoxicillin for 7 days, following which swelling subsided in 15 days. The systemic side effects like fever and myalgia were presented in 5 patients $(16.6 \%)$ associated with chills on the day of first dose of injection. They were treated with Tablet Paracetamol $650 \mathrm{mg}$ following which symptoms subsided and have no recurrence with subsequent injections.
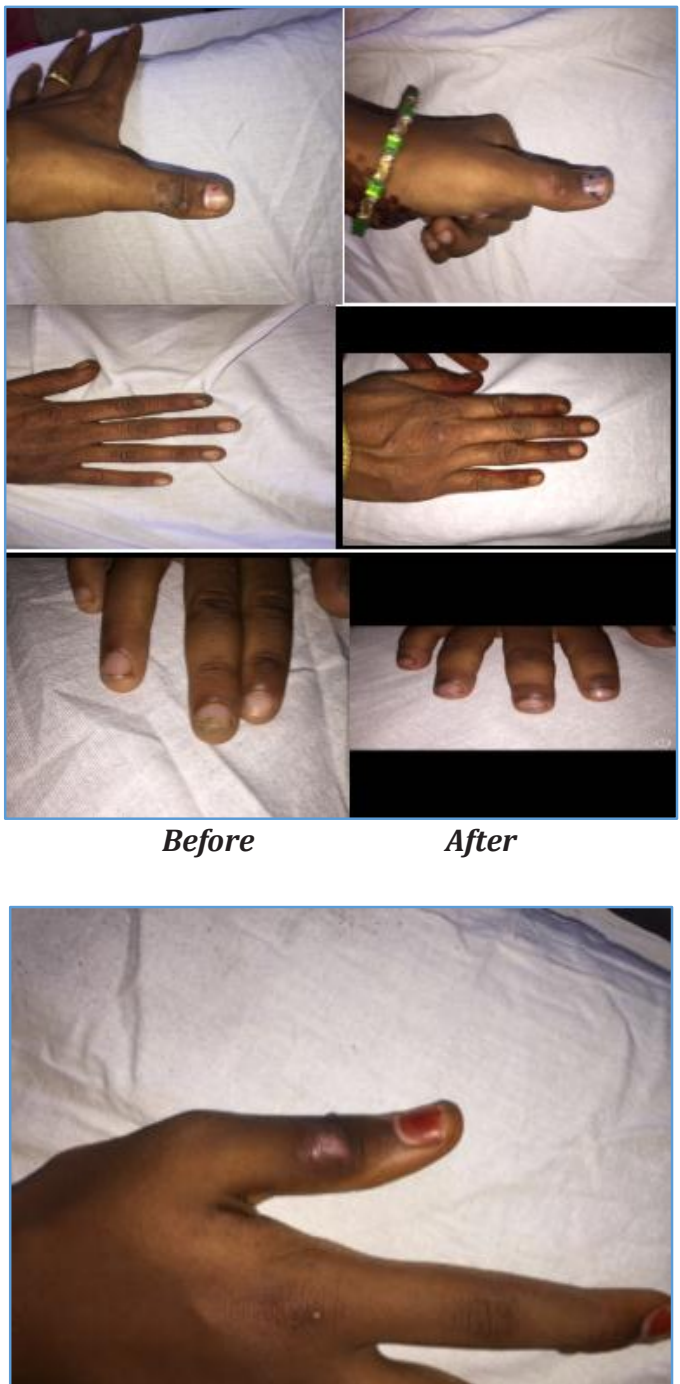

Figure 1. Indicates Local Complication Swelling 


\section{DISCUSSION}

Cutaneous warts caused by Human Papilloma virus affects all age groups but is most prevalent in children and young age. A multitude of therapeutic modalities exist but no single agent is invariably effective. Although spontaneous remission in children occurs within 2 years, in adults, spontaneous recovery is much slower and takes longer time. As warts are cosmetically unacceptable most of the patients approach for treatment. There are various methods of treatment available including topical therapies (salicylic acid 12-26\%, topical TCA, podophyllotoxin $0.5 \%$, topical $5 \mathrm{FU}$ ), systemic therapies (oral cimetidine, oral retinoids, cidofovir) and surgery (electrocautery, curettage, cryotherapy). Each modality has its own limitations and side effects.

Cell-mediated immunity is said to play a major role in pathophysiology of warts, therefore, this led to the stimulation of cell-mediated immunity for treatment of warts leading to the usage of immunomodulators like purified protein derivative (PPD), measles, mumps, rubella vaccine (MMR) and most recently Bacillus-Calmette Guerin vaccine (BCG). Intralesional immunotherapy is cost effective when compared to traditional therapy for warts. Aldahan demonstrated in his review that intralesional BCG was considered to be a cheaper one. Our study with BCG vaccine was considered cost effective as it costs Rs 51 per vial. Significant improvement of warts not only at injected site but also at distant untreated warts were seen. Systemic side effects like fever and myalgia occurred were transient and responded well to treatment. Local side effects like swelling and redness also subsided within 15 days after taking medication and none have ulcerated.

In a study by Khakoo et al., $0.1 \mathrm{~mL}$ BCG vaccine was given intralesionally to a 21-year-old female patient with plantar warts, for which numerous attempts were done with unsuccessful medical and surgical procedures previously. The patient had total resolution of plantar warts with single injection and had no recurrence during 3 months followup but observed granulomatous hepatitis.

A study by Malison et al, on 6 patients ( 5 males, 1 female) with condylomata acuminata where in all patients, traditional therapy failed, were treated with BCG vaccine weekly once with no significant improvement among all and with intense local pain as side effect. This study failed because of improper intralesional injection technique. ${ }^{1}$

A Study by Sharquie et al in 2008 have selected two groups of patients with cutaneous warts, 81 patients in group I, who received BCG vaccine in 1-3 doses with one month interval and group II with 73 patients were injected with distilled water. 30 patients $(39.7 \%)$ out of 81 patients in group I showed complete recovery. There was no recurrence for a period of 3 months and no side effects were observed. ${ }^{2}$

In 2013, Yosef et al injected intralesional BCG vaccine into a 48-year-old male with troublesome huge wart on left little toe of 5 years duration and did not respond to any treatment. The BCG vaccine was injected intralesionally into the wart at 2 weeks interval and observed complete clearance by the end of fifth injection. He presented with side effects like oedema at site of injection and Flu like illness that subsided within 3 days. $^{3}$

In Kumar P and Das A et al study, a 26-year-old man with recalcitrant periungual wart was treated with intralesional BCG vaccine $0.1 \mathrm{~mL}$ with 2 weeks interval for a total of 3 injections. The patient had complete recovery with associated side effects like intense pain and ulcer at site which healed with scar formation. ${ }^{4}$

In 2017, Sahar Alsharif published a case report on intralesional immunotherapy with BCG vaccine for treatment of warts on a 21-year-old male patient with multiple warts over both hands and neck for 1 year duration. Patient was treated with conventional therapy but did not show any improvement. Intralesional BCG vaccine $0.1 \mathrm{~mL}$ was injected at 2 weeks interval with complete clearance after third session. No side effects and recurrences were observed. ${ }^{5}$

The clearance rate for extragenital warts with immunotherapy ranged from 39.7 to $87 \%$. Our study with BCG vaccine for clearance of warts was similar to other immunomodulators used for treatment of warts in other studies. We have selected two-week interval session of BCG vaccine as it has shown better results when compared to weekly once and monthly once sessions shown in the previous studies. $40 \%$ of patients (12 out of 30 ) showed complete clearance with single injection and $2.7 \%$ of patients (8 out of 30) showed complete clearance with two doses of injections. Side effects, both local and systemic were transient and responded well to medication without any further complication (such as granulomatous hepatitis and ulceration observed in previous studies). The dose was standardised to $0.1 \mathrm{~mL}$ of BCG vaccine as recommended by the manufacturers, so the same dose was used to treat warts for all the 30 patients selected for the study.

\section{CONCLUSION}

There are various treatment modalities available for treatment of warts (topical, systemic and physical therapies) with variable results and side effects. Immunotherapy was introduced for warts treatment as cell-mediated immunity is considered to play a key role in treatment of warts. Among various immunomodulators available, BCG vaccine was selected for our study because of its cost effectiveness, significant improvement in both injected as well as distant untreated warts, minimal treatable local and systemic side effects and complete clearance observed with minimal number of injections. As $86.6 \%$ of patients in our study treated with intralesional BCG vaccine showed complete clearance of warts, there seem to be definitive role of this immunotherapy in treatment of warts.

\section{REFERENCES}

[1] D'Alesandria RM, Khakoo RA. Granulomatous hepatitis in a healthy adult following BCG injection into plantar wart. Am J Gastroenterol 1977;68(4):392-5.

[2] Malison MD, Salkin D. Attempted BCG immunotherapy for condylomata acuminate. $\mathrm{Br} \mathrm{J}$ Vener Dis 1981;57(2):148.

[3] Sharquie KE, Al-Rawi JR, Al-Nuiamy AA, et al. Bacille Calmette Guerin immunotherapy of viral warts. Saudi Med J 2008;29(4):589-93.

[4] Kumar P, Das A. Excellent response to intralesional Bacillus Calmette Guerin vaccine in recalcitrant periungual wart. J Gynecol Obstet 2009;7(4):234-5.

[5] Alsharif S, Alzanbagi H, Dania M. Intralesional immunotherapy with Bacille Calmette-Guerin (BCG) vaccine for the treatment of warts: case report and systematic review. Int J Biol Med Res 2017;8(1): 5820-6. 